\title{
El divorcio y la responsabilidad por daño moral Santos Cifuentes
}

\section{PLANTEAMIENTOS DE LA CUESTION}

T NA DE LAS CONSECUENCIAS de la ruptura de la unión matrimonial, cuando a ella se llega por causa exclusiva de un cónyuge, es la indemnización al inocente declarado tal por sentencia. La aspiración de obtener, además de las ventajas en que se coloca cuando logra hacer recaer la culpa del fracaso en el otro, la responsabilidad derivada de los dafios que la conducta antijurídica haya podido producir, no se ha dejado de considerar $y$ ha sido motora de opiniones y jurispradencia encontradas. Se trata no solo de la pretensión de resarcimiento del daño material, sino también del moral. Este último es el aspecto que a continuación desarrollaré.

Desde ya que se descarta la admisión de la demanda si los dos cónyuges han sido causantes del divorcio; pero este principio, sin embargo, podría tener desviaciones a lo mejor insospechadas, según la base reparatoria en que se coloque el pensador, o bien la ley positiva vigente, Porque, en efecto, por una parte puede ser que el régimen jurídico prevea esa indemnización en favor del inocente, pero solo teniendo en cuenta los hechos que llevaron a la desunión conyugal; bien, por otra, que no existe norma especifica regulatoria de dicha responsabilidad, debiendo acudirse a los principios generales de la obligación de responder por hechos antijurídicos, cuestión que suscita serias dudas, como ocurre en el derecho argentino; o bien, que el régimen jurídico especial al acogerla con amplitud permita fundar la indemnización por los causales del divor- 
cio; aủn más, por el divorcio en sí mismo, al margen del juzgamiento de los hechos y de las causales que lo sustentaron. En el segundo supuesto, cualquiera de las respuestas puede ser correcta; ya que, al no haber previsión legal al respecto, se da ancho y desordenado marco a las elucubraciones doctrinales y a las decisiones de los jueces, pudiendo arribarse a la idea de que si responde por la conducta productora del divorcio, habiendo culpas recíprocas, nada impide investigar si fue uno solo de los comportamientos conyugales el que tuvo repercusiones dafosas en la csfera de afección o sentimientos, siendo el del otro cónyuge imputable pero no causante de tal perjuicio. Por ejemplo, frente a una injuria no muy notoria ni incisiva - producto de la mera indiferencia-, un adulterio escandaloso de origen y trayectoria mortificantes en grado sumo. Podria hasta pensarse en la compensación del crédito por daños hasta el de menor cantidad, pues si las culpas no pueden compensarse para neutralizar o modificar el divorcio, distinta cosa es lo que aparece en el área de las consecuencias dañosas de las actitudes imputables, al ser mayor o menor la incidencia de esos actos, causales o efectos de la frustración matrimonial, de uno con relación al otro de los cónyuges divorciados que incurrieron en culpas reciprocas.

No habré de detenerme en la naturaleza juridica del dafo moral, dejando sentado en este introito que sigo la corriente de la teoría resarcitoria y que no particípo de la sancionatoria (sanción ejemplar), ni de la que eclécticamente amalgama ambas, pretendiendo dar una solución ambigua y confusa, porque o se considera que el prototipo de las consecuencias de los hechos en el orden jurídico privado es reparatorio, o que tiene base represiva. Pero las dos cosas juntas es inconsistente y no satisface las exigencias de la razón lógica. Esa índole resarcitoria, perteneciente al derecho civil, asienta en la idea de satisfacción y descarta la de la equivalencia que es propia del daño material. A partir de tal base jurídi, ${ }_{i}$, al llegar al antecedente causal de la indemnización, se ponen de manifiesto varias cuestiones sustanciales y procesales. Una de ellas es la holgura con que el juzgador puede aquilatar los hechos y la satisfacción reparatoria, la cual escapa a lós esquemas rígidos del quantum tasado o que se acredite con base cierta, para penetrar en la más difícil consideración de los valores de sentimientos afectados. Otra, es la prueba o elementos de juicio para juzgar la existencia del daño moral y su entidad, la cual generaimente surge de los hechos en sí mismos (in re ipsa loquitur), de donde se eleva la presunción hóminis de la existencia del perjuicio.

Tales principios que suelen mayoritariamente admitirse como pertenecientes a la esfera extrapatrimonial de este dano, sea que tenga origen 
contractual o extracontractual, cuando se los aplica al matrimonio y su disolución causada por la culpa, dan un panorama confuso y de no fácil encuadre para atender a una de las tres respuestas posibles: los hechos que provocaron la ruptura, las causales en que se fundan o el divorcio en sí con independencia de la gravedad de esos hechos y causales. La cuarta sería simplemente negativa, es decir, sostener que en este caso, frente a la institución matrimonial, es inadmisible la indemnización del dafio moral.

Desde ya, que si se siguiera la corriente amplia expuesta y la de que basta el divorcio y su declaración de culpa como antecedente del derecho a exigir la reparación, tendrían que considerarse los daños posteriores a la sentencia que lo declaró, o sea, la tribulación causada por la disolución matrimonial decretada. Habría de ser materia de un nuevo juicio que se ocupe de la frustración matrimonial y sus efectos.

Haciendo un resumen de los planteamientos y sus soluciones, hay cuatro respuestas: a) la que admite la reparación del daffo moral atendiendo a los hechos que dieron causa al divorcio; b) la que lo acepta por la indole de las causales probadas o juzgadas; c) la que permite establecerlo por la frustración mortificante de la unión producida por el divorcio decretado, y d) la que niega toda clase de resarcimiento del daño moral.

\section{LA TEORIA NEGATORIA}

Los autores que se opusieron a la indemnización han explayado dos argumentaciones. Unos, como Bibiloni (1), Borda (2) y Llambias (3), por entender que todo reclamo en este sentido no es moral. Dijo el primero de ellos, al dar un ejemplo con la más grave de las causales (según la doctrina tradicional), el adulterio, que la acción del daño genera una especie de repulsión instintiva, sublevándose la conciencia moral ante semejantes reclamos.

(1) BIBLLONI, Juan Antonio. "Anteproyecto de Reformes al Código Civit Argentino", Buenos Aires, 1929, t, 2, p, 510 y ss.

(2) BORDA, Guillermo A. "Tratado de Derecho Civil Argentino. Derecho de familia", 4a. ed. Buenos Aires, 1969, t. 1, n. 548 ter.

(3) LLAMBiAS, Jorge J. "Tratado de Derecho Civi, Obligaciones", Buenos Aires, 1967, n. 23, En nota 31 dice este autor: "Así, segín nos parece, no es admisible que uno de los esposos, inocente del diwordio, reelame del otro el resarcimiento del daho que le crusa en el incumplimiento del deber de fólidad conyugal..... 
Borda sostuvo que era contrario a la sensibilidad argentina y renida con la moral y buenas costumbres eso de pretender, en el caso de infidelidad, lucrar con la deshonra. Y, Llambias, haciendo mérito de la nobleza de sentimientos que los esposos se han tenido recíprocamente, entendia que no era adecuado degradarlos con pretensiones resarcitorias de tal indole.

La segunda fundamentación negativa, ante el silencio de la ley argentina matrimonial, hace hincapié en la especialidad de este derecho, lo que inhibiría aplicar las normas generales de la responsabilidad por daños. En tal caso se colocaron Díaz de Guijarro (4), y Molinario (5).

\section{OPINION AFIRMATIVA LIMITADA EN EL DERECHO ARGENTINO}

A mi modo de ver, es sumamente importante lo que ha enseñado Díaz de Guijarro sobre la especialidad del derecho de familia y la necesidad en esto de las reparaciones, de no mezclar los problemas para no entorpecer ni debilitar las instituciones en lo que tienen de propio y diferente.

Parto de esa posición, pues el matrimonio como acto juridico, trayectoria vital, de derechos y obligaciones que lo acompañan, pero, particularmente, causales de rompimiento en el origen y entrafia de la desunión que lleva al divorcio de los cónyuges, no ticne ni por asomo semejanza con lo que ocurre en otros ámbitos negociales, ni con lo que ocurre frente a la responsabilidad por hechos ilícitos o por incumplimientos contractuales. No es igual, ni lo puede ser, la injuria de la calle, la lesión personal y el ataque o la ofensa a la persona, o la mora contractual, que la injuria del conyuge y, en general, la generación de las causas que motivan la separación y el divorcio. $\mathrm{Y}$ no es lo mismo porque en un caso se necesita el dano, la imputabilidad y la autoría (voluntad sana) -previo examen de la relación de causalidad-, para que nazca el correspondiente derecho a obtener la reparación. En el otro hay una conjugación de comportamientos recíprocos singulares, que parten de la muy entrañable pasión del amor y que llegan al trato de todos los días, en la

(4) DIAZ DE GUUARRO, Enrique. "Improcedencia del resarcintiento del dafo maval en el juicio de divorcio y su admikibutida en la mulidad del marrimonio"; J.A. 1983-111-625.

(5) MOLINAR1O, Albeito D. "Responsibilidad civil", Cótdobs, 1984, p. 398, ss. 
convivencia (casa, mesa y lecho); en la interferencia intersubjetiva (al decir de Cossio) del hombre y de la mujer unidos en matrimonio.

El sólo desamor (intencionado o inculpable) puede ser causa de injurias y de divorcio. Porque el matrimonio quiere actitud tolerante, mucho más allá que la tolerancia corriente; comprensiva de aquellas cosas que común e individualmente al ser humano no se le exige que comprenda; intima, con una intimidad que sobrepasa la del sujeto solo; compenetración entre dos, como consecuencia de la multiplicidad permanente de momentos comunes, de aspiraciones conjuntas, de proyectos compartidos, que es mucho más asidua y acendrada de cualquier unión de personas por la amistad, sea por los negocios, por aspiraciones intelectuales, etc.

Pues bien, la ruptura de todas csas filiaciones espirituales, tan especiales y delicadas, o de aiguna tan sólo, puede ser la causa de la ruptura, del enojo y de la culpa; la contrapartida de la inocencia declarada en un fallo judicial. Pienso que ninguna, por si sola, al margen de la unión matrimonial y sus implicancias, podría generar un derecho al resarcimiento de daños materiales o morales. De ahí que me convence la idea de la especialidad en el orden jurídico, $y$ la necesidad de aguzar los sentidos y la interpretación, cuando se pretende trasladar la solución común al desenlace matrimonial.

Comparto, en general, por tanto, las conclusiones del tratadista citado -ya se verá la diferencia-, en el sentido de que es autónomo el régimen de sanciones que reglamenta el divorcio. La legislación argentina no contempla el resarcimiento material o moral pecuniarios; to que se observa claramente de la idea de que ni el Código de Vélez, ni la ley $2393 \mathrm{ni}$ la actual ley 23.515 , establecieron una remisión al sistema reparatorio común por responsabilidad extracontractual o contractual, ni una regulación independiente al respecto, consagrándola por causa del divorcio y el establecimiento de la culpa al declararlo. Sintomáticamente, pero muy sintomáticamente, esos sistemas jurídicos, que silencian la cuestión frente al divorcio, la establecen cuando se trata de la nulidad del acto matrimonial, y reglan, aqui si, la posibilidad de reclamar al cónyuge de buena fe una indemnización de daños y perjuicios. El silencio $\mathrm{u}$ omisión sobre lo otro, la ausencia de alguna pista legal para considerar una remisión al art. 1066 y sigtes. del cód. civil, dan cuenta de una clara voluntad; pues, cuando se trata de expedirse y establecerlo, se lo ha hecho expresamente en la nulidad (art. 225, cód. civil vigente), pero no en el divorcio.

Si se une esta idea exegética, extraf́da por comparación lógica y 
coherente, con las bases teleológicas expuestas, sobre la diferencia real y vivida de unas obligaciones y de otras, de unas conductas y de otras, en fin, de la mancomunidad corporal y espiritual tan singular del matrimonio, frente a las conductas del individuo con sus semejantes, se advierte que este silencio es fundado y exprofeso; 0 , en todo caso, que el legislador ha resuelto estando particularmente preocupado por no interferir un aspecto de la vida (el matrimonial), con bases genéricas propias de las personas particulares $y$ sus derechos.

$\mathrm{Y}$, las contestaciones vienen solas a las preguntas: ¿cómo se podria decir que hay derecho de indemnización al dafio moral por la circunstancia de que un cónyuge dejó de amar al otro y lo manifestó públicamente, infiriendo por sólo eso una injuria grave?; ¿qué la mujer desatendió al marido simplemente porque, siendo la encargada singular de su hogar, no se ocupó de hacerle la cama, la comida y lavarle la ropa?, ¿qué, en fin, el marido se portó indiferente en sociedad, un algo despreciativo, un algo desaprensivo, hiriendo las justas susceptibilidades de la mujer?. Todo esto podría dar causa al divorcio, pero no podría sostenerse que da motivo al daño moral reparable. Es que frente a esos comportamientos, ya aceptados como agraviantes por la jurisprudencia, existe la reparación propia de la institución de que se trata: la declaración de inocencia, con los correspondientes efectos. Agregarle dahos seria excesivo.

La declaración de inocencia y la contrapartida, la de culpabilidad del otro, es por si un desagravio; esta empresa espiritual común, se dice a la sociedad, falló, se quebró por tu culpa; "sos" el responsable de la separación matrimonial. Pero, además, por ello, quedás desheredado si se trata de la separación sin disolución vincular (art. 3574, cód. civ.), y en este caso el inocente conserva la vocación hereditaria. Se agrega que ahora cualquiera de los esposos declarado inocente deberá contribuir a que, el otro, lo mantega en el nivel de vida que tenia durante la convivencia (art. 207 actual cód. civil); distinta cosa a cuando hay declaración de culpabilidad, en que esa obligación alimentaria sólo aparece frente a la imposibilidad de sostenerse, si el otro tuviera medios (art. 209).

También ahora aparece una sanción pecuniaria de un matiz muy particular; el inocente o el cónyuge enfermo tienen derecho a continuar ocupando el inmueble que fue el asiento conyugal habitado por ellos durante el juicio (arts. 202 y 203, cód. civil). Y se revocan las donaciones 
por el cónyuge que no dio causa al diworcio, como otro aspecto de la especialidad matrimonial (art, 212, cỏd, civ.) (6).

La pregunta es: ¿No ha considerado el legislador suficiente reparación todos estos derechos del inocente, como para a la vez tratarlo como si fuera un particular damnificado que tiene derecho al daño moral? $\mathrm{y}$, ¿qué es sino todo aquello una neutralización del dafio por la culpa en el divorcio; una compensación satisfactoria que suplanta por sus peculiaridades propias a la del art. 1078 del cód. civ.?

Puestos del lado de la teoria de la pena ejemplar, que no comparto, ¿no sería sanción acabada la culpa declarada y esos efectos entrelazantes, pecuniarios algunos, sacrificados otros? Queda ligado a pagar alimentos al cónyuge inocente sin convivir con él; sin gozar con él las felicidades matrimoniales, sin estar en la empresa común para obtener los medios. Pierde la vivienda que aprovecha el otro; y la herencia .... etc.

Reconozco que la doctrina mayoritaria argentina ha sostenido que se aplican las bases reparatorias comunes (7).

Sin embargo de que con tanta amplitud no la comparto, me parece que debe hacerse una distinción, la cual no tiene arraigo expreso, como

(6) BOSSERT, Gustavo A. y ZANNONI, Fdurdo A. "Manual de derecho de familia", Astrea $1988, \mathrm{p}, 297$ y sigtes.

(7) BARDERO, Omar U.: "Daflos y pertuleios derìados del divorcio". Buenos Aires, 1977; BELLUSCIO, Augusto C. "Daños y periuícion derivados del dirorcio", en "Responsabilidod civil en el derecho de familia", Buenos Aires, 1983, ps. 3/55; RFBORA, Juan Carlos: "El defo moral", ob. cit., J.A. 14 sec, doct,- I00; SAL AS, Acdeel Emesto: "Indemnización de los danos derivados del dimancio". J,A. 1942-11-1011; ACUNA AANZORENA, Arturo: "Reppon. sabilidad civil del cónyuge adilitero y en cómplice por causa del adulterio", L.L. 26-21 2, y en "Esnudios sabre la responsabilidad civil", La Plata, 1963, p. 223; COLOMBO, Leonardo: "In. demnización del dễo producido por el adulterio de la erposa"" L.L 89-708; GUSTAVINO, Elías At: "Prescripeión de le simulaciön entre cányuger $y$ derecho locativo ganancial": I.A. 1965-V.471, y en "Divorcla", en Revista Forense, Saata Fe, 1970, D. 35; SPOTA, Alberto: "Tratado de Derecho Gril", Buenos Aires, 1968, t. 12, p, 149, y en "Sohre las reformas at Codigo Cival", Buenos Aires, 1969, p. 148; LOPEZ DEL CARRIL, Jullo J.: "El derecho de familit en lo problemdrica contemponanea", Buenos Aires, 1968: MAZZINGHI, Jorze A.; "Denchlo de familia". Buenos Aires, 1972, t.2, n.159; MOSSET ITURRASPE, Jorge: "Respansublilidud por doflos", Buenas Airres. 1973, t. 2-B, p. 225, y "Los dañas emergentes del divon

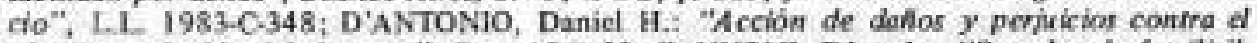
cónyuge cuipable del divorcio", Zeus 10-D-33; ZANNONI, Eduando: "Derecho de familia". Buenos Aires, 1978, t, 2, p, 175 y ss.; MANCHINI, Hóctor L. "Resarcimiento de daños y perpicicios a course del divarcbo", J.A, $1986+1-727$; MAKIANICH DE BASSET. Lidia N... "Otra aceriada acogida del derecho a reparación de las defios ocasianados por el cányuge cuipable de divarcio". E. D, 115-844, BUSTAMANTE ALSINA J, "Dónoncio y resp. civi" L.L. diario del día 16 de setiembre de 1988. 
se ha visto, en la ley, pero que sí hay buenos motivos legales y de justicia para considerarla en aceptable interpretaciôn sistemática.

En efecto, el principio negativo tiene en cuenta el divorcio en sí mismo. Es decir, frente al divorcio y la declaración de inocencia no hay bases como para sostenter la aplicación de las normas comunes de responsabilidad por daño moral y condenar a una satisfacción pecuniaria afiadida a las que ya la ley contempla. Pero, otra cosa pueden ser los hechos que llevan al divorcio, si esos hechos tienen una expansión y gravedad que por sí, al margen de la separación conyugal y de su disolución, entraffen un verdadero daño moral agregado a la persona del cónyuge.

En concreto, el divorcio no es causa de resarcimiento, las causales tampoco, pero los hechos que llevaron al divorcio, cuando ellos tienen fuerza dafadora muy punzante, en el prestigio, en las esencias comunes espirituales, en lo físico u orgánico, podría verse además malogrado la unión conyugal, una lesión al bien moral que debe ser compensada con carácter autónomo. Asi, por ejemplo, la causal fue motivo de divorcio, pero los hechos que la configuraron tuvieron una repercusión dañosa que se agrega: insulto en público de amigos con un verdadero escándalo, endilgando inmoralidades muy bajas. No es igual que el cónyuge le diga a su mujer ese insulto en reductos más o menos cerrados, a que lo proclame en público (sos una r. ... un p...) El aduiterio manifestado, desembozado de modo tal que se produzca un rebajamiento entre otros, un ataque a la dignidad del cónyuge. Los golpes que dejan marcas y entrañan sufrimientos muy graves (hospitalizaciones; tratamientos médicos, etc., y hasta incapacidades futuras).

Aunque la ley argentina no lo haya previsto, según se ha visto, tales consecuencias de los actos que van más allá de la culpa en el divorcio para entrar en el campo del ataque personal, o sea, unidos a esa culpa pero separables por sus consecuencias en el dano a la persona en virtud de la gravedad de los hechos, vienen a mezclar los terrenos jurídicos y aquí, si, aparte del divorcio, me parece de toda justicia amparar los derechos personalisimos heridos aplicando las normas del código, Pero debe de tener en cuenta por el juzgador la indole dolorosa y acentuada del ataque que sobrepase la mera relación matrimonial en sus implicancias, culpas y quicbras. Pues, en estos supuestos de gravedad se penetra en los dos regímenes, el matrimonio por un lado, con el divorcio como término final. $Y$ el dafio a la persona al margen del divorcio que no puede quedar impune; pues, se ha sobrepasado la protección y el derecho del inocente que viene por línea del régimen normativo de la familia. 
El empleador puede despedir a su empleado y se obliga a una indemnización tarifada, pero si lo hace calumniándolo (denuncia de un delito que no ha cometido), o insultándolo, o cometiendo otro delito con aquél, la cosa cambia, y deben repararse aparte de las consecuencias por la pérdida del empleo, las otras consecuencias dañosas del acto ilícito (8). De igual modo es dable razonar frente al desquicio matrimonial.

\section{EL DERECHO COMPARADO}

Esta solución que revierte el asunto a las normas generales sobre la responsabilidad de las personas in genere, tiene la fuerza de su consagración legislativa extranjera. Asi, el derecho suizo la establece, en el art. 151 del cód. de 1907: "Si los hechos que han determinado el divorcio han causado un grave ataque a los intereses personales del esposo inocente, el juez puede conceder además una suma de dinero a título de reparación moral". Lo que demuestra que el daño moral procede si hay gravedad en la acción, gravedad que excede la medida habitual de la culpa en el divorcio, y la cual queda librada a la apreciación del juez. La acción por la reparación de estos hechos es personalísima y accesoria al juicio de divorcio, o autónoma por la responsabilidad cuasidelictual.

La doctrina y jurisprudencia alemana, ante el silencio del código, consideraban, antes de 1977, que si la falta del cónyuge culpable constituye, a la vez (lo subrayo), una violación de principios generales de los hechos ilícitos, la victima tiene derecho de daños en forma independiente (Esener y Kipp y Wolff, cits. por Belluscio).

El código civil griego, de 1920, consagra solución parecida, art, 1453: "Si el hecho que ha constituido la causa del divorcio ha sido ejecutado en condiciones que comportan una grave ofensa a la persona del cónyuge no responsable, el tribunal puede, en la sentencia de divorcio, obligar a la parte que sea única responsable a pagar a la parte no responsable una suma de dinero en razón del dafo moral".

De igual modo, el código matrimonial sueco de 1920 y la ley danesa de matrimonio de 1922, que habla en su art. 67 del cónyuge que "ha ultrajado groseramente al otro". En similar solución se encuentra el código

(8) DE LA FUENTE, "El doño moral en el contrato de trabsjo", L.1. 1981-C-800, en especial, P. 810. 
del Perú de 1936, art. 264: "Si los hechos que han determinado el divorcio comprometen gravemente el interés personal del cónyuge inocente, el juez puede concederle una suma de dinero a título de reparación moral". Con ligera variante de redacción, tal es la norma del actual Código peruano de 1984 (art. 351).

Son las soluciones que considero más ajustadas a la equidad y al sistema del divorcio, sanción prevaleciente en las legislaciones como la argentina.

Sólo es dable considerar más allá de las sanciones propias al régimen del divorcio, las que entrañen un verdadero grave ataque a la persona del cónyuge inocente, porque éste es tal como cualquiera (soltero, viudo, trabajador o empleador, casado, divorciado, etc.) La relación matrimonial no puede servir de puente a un detrimento moral autónomo que no sea reparado, cuando ese detrimento es superior en su gravedad al que produce la mera ruptura del matrimonio y sus consecuencias legales. 